\title{
Alcohol use in schizophrenia: prevalence, patterns, correlates and clinical outcomes in Goa, India
}

\author{
Anil Rane, ${ }^{1}$ Abhijit Nadkarni, ${ }^{2}$ Jaiprada Kanekar, ${ }^{1}$ Wenona Fernandes, ${ }^{1}$ Hirabai A. Borker, \\ Yvonne Pereira'
}

The Psychiatrist (2012), 36, 257-262, doi: 10.1192/pb.bp.111.036459

${ }^{1}$ Institute of Psychiatry and Human Behaviour, Goa, India; ${ }^{2}$ London School of Hygiene and Tropical Medicine, UK Correspondence to Anil Rane (dranilrane@rediffmail.com) First received 15 Aug 2011, final revision 6 Jan 2012, accepted 9 Feb 2012

\begin{abstract}
Aims and method To explore the patterns of alcohol consumption and its impact on clinical outcomes in schizophrenia in low- and middle-income countries. We performed a cross-sectional survey of 315 patients with schizophrenia and calculated the prevalence of alcohol consumption and alcohol use disorder. The patients' sociodemographic profiles and clinical outcomes, including Brief Psychiatric Rating Scale (BPRS) scores, were compared between abstainers and drinkers using the $\chi^{2}$ - and $t$-tests.

Results The 1-year prevalence of drinking, hazardous drinking and alcohol dependence was $16.8 \%$ (95\% Cl 12.9-21.4), 5.7\% (95\% Cl 3.4-8.9) and 2.5\% (95\% Cl 1.1-4.9), respectively. Male gender, single or post-marital status, higher education and being economically active were significantly associated with alcohol consumption. Alcohol drinkers were significantly more likely to be on combination psychotropics compared with abstainers. The mean total BPRS score was significantly lower in alcohol drinkers compared with abstainers. Drinking alcohol was associated with fewer deficit symptoms.
\end{abstract}

Clinical implications Cultural settings have a significant impact on the prevalence of alcohol use disorder in schizophrenia.

Declaration of interest None.
Schizophrenia with comorbid substance misuse, despite being extensively studied, continues to raise diagnostic queries and poses a management issue across services. The prevalence of comorbid substance use disorder in people with schizophrenia varies widely, from $10 \%$ to $70 \% .^{1}$ The wide range is partly the result of variability in study design, including variability in measurement of schizophrenia and substance use and the type of sample studied (e.g. in-patients $v$. out-patients, clinical $v$. community).

Most North American studies estimate that roughly $50 \%$ of people diagnosed with schizophrenia also meet criteria for substance use disorders. ${ }^{2-6}$ In the Epidemiologic Catchment Area study, 33.7\% of people with a lifetime diagnosis of schizophrenia or schizophreniform disorder met criteria for alcohol disorder; and compared with those without schizophrenia, the odds of having an alcohol disorder were over three times higher in people with schizophrenia. $^{2}$ Similarly, European studies have shown high rates of substance use disorders in people with schizophrenia. ${ }^{7,8}$ In the UK, the 1-year prevalence of alcohol problems was $32 \%$ in psychoses ${ }^{9}$ and $11.7 \%$ in first-episode psychoses. ${ }^{10}$ In a UK community study, $24 \%$ of people with severe mental disorders reported substance misuse, including alcohol misuse (61\%), in the previous 12 months. ${ }^{11}$ In a study from London, $22.1 \%$ of people with schizophrenia had a lifetime history of problem drinking. ${ }^{12}$ In a community sample in Australia, the prevalence of lifetime diagnosis of alcohol use disorder in psychosis was $38 \%$ in men and $17 \%$ in women, ${ }^{7}$ and current use of alcohol in a clinic-based sample of schizophrenia was $77.3 \% .^{13}$ Among low- and middle-income countries (LAMIs), a crosssectional study from São Paulo, Brazil, reported the prevalence of alcohol misuse or dependence in non-affective psychoses to be $7.3 \%$, much lower than the American and European rates. ${ }^{14}$ The only Asian data, from a study in Singapore, reported lifetime prevalence rates of $15.8 \%$ ('mild' use) and $10.3 \%$ ('heavy' use) in schizophrenia and schizophreniform disorders. ${ }^{15}$

Comorbidity of substance use in schizophrenia has been associated with adverse outcomes, including higher symptom ratings, poor treatment responses, relapses, frequent hospitalisation, non-adherence, tardive dyskinesia, HIV infection, hepatitis $\mathrm{C}$ infection, suicide, and a range of psychosocial difficulties such as violence, victimisation, incarceration, homelessness and family problems. ${ }^{12,16-31}$ Other studies, however, have contradicted these findings or failed to identify robust relationships between the severity of schizophrenic symptoms and substance misuse. $^{1,12,32-37}$ Some studies have failed to show the 
increased frequency of hospital admissions as reported above. $^{1,38}$

The aims of our study were to assess the prevalence of alcohol consumption in a clinical sample of patients with schizophrenia in Goa, India; to investigate the pattern and correlates of alcohol consumption in schizophrenia; and to determine the effect of alcohol consumption on clinical outcomes in schizophrenia.

\section{Method}

The setting was the out-patient department of a 190-bed postgraduate university teaching hospital that provides tertiary care mental health services to Goa, one of the smallest states in India. About 100 patients use out-patient services at this hospital every day.

People with schizophrenia who attended out-patient services for at least 12 months and attended follow-up in the 3 -month study period were recruited. Diagnosis of schizophrenia was ascertained from case paper records. Patients aged under 18 years or over 65 years were excluded.

\section{Measurement}

A structured questionnaire was developed to achieve the study objectives. Data were collected over a 3-month period. Information was gathered from patients, family members and case paper records by two psychiatrists (J.K. and W.F.). The questionnaire was used to collect information in the following domains:

- Sociodemographic profile: participants' age, gender, education, occupation and marital status, who they were living with, and whether they were in receipt of disability benefits.

- Alcohol consumption: most preferred drink, preferred place for drinking, age at first drink, morning drinking, drink in past week/month/year/ever, and alcohol consumption in first-degree relatives. Alcohol consumed was assessed as beer, Indian-made foreign liquor (whiskey, vodka, gin, brandy, rum) or country liquor (locally brewed and distilled spirits made from cashew fruit or coconut palm).

- Alcohol use disorder: this was measured using the Alcohol Use Disorders Identification Test (AUDIT), a ten-item screening questionnaire developed by the World Health Organization (WHO) ${ }^{39}$ The AUDIT has been validated and used in cross-national studies, including in India. ${ }^{40-42}$ For a previous study, the AUDIT has been translated into Konkani (Goan vernacular) using the translation-back-translation method with two teams of translators, followed by an item-by-item analysis and selection by consensus. ${ }^{43}$ The WHOprescribed AUDIT cut-off score of 8 was used to detect hazardous drinking. Participants who drank alcohol but scored below the cut-off score of 8 were coded as casual drinkers. Alcohol dependence was diagnosed using the ICD-10 diagnostic criteria for research. ${ }^{44}$

- Clinical correlates: duration of psychotic illness, number of in-patient admissions and total in-patient days in the past 12 months, current treatment (typical/atypical/ depot antipsychotics and other psychotropic medication), dose of antipsychotic in chlorpromazine equivalents, number of out-patient contacts in the past year, and history of mental illness in first-degree relatives. The Brief Psychiatric Rating Scale (BPRS) was used to assess the psychopathology and severity of illness. ${ }^{45}$ The BPRS was administered to all participants by a senior psychiatrist (A.R.) who was masked to the AUDIT scores. The BPRS has been used for studies on schizophrenia in India. $^{46}$

\section{Analyses}

All sociodemographic variables (except age) and clinical outcomes (except the number of in-patient days, chlorpromazine equivalents and BPRS scores) were analysed as categorical variables. Age, number of in-patient days, chlorpromazine equivalents and BPRS scores were analysed as continuous variables. Occupational status was converted into a binary variable by coding unemployed people and homemakers as economically inactive, and full-time or part-time workers as economically active. Marital status was converted into a binary variable as married and single/ post-marital (widowed/separated/divorced). Living circumstances were converted to a binary variable by combining living alone with living in supported housing. The duration of illness, number of in-patient admissions and number of out-patient visits were converted to categorical variables. The prevalence of drinking and alcohol use disorder was calculated with $95 \%$ confidence intervals. Sociodemographic characteristics and clinical outcomes in the two exposure groups (drinkers, abstainers) were summarised in the form of proportions and means and compared using appropriate statistical tests $\left(\chi^{2}\right.$-test to compare proportions, $t$-test to compare means). A $P$-value of less than 0.05 was considered to be statistically significant. All analyses were performed using STATA 10.0 for Windows.

\section{Ethical considerations}

Informed written consent was sought before participation in the study. Participants were free to withdraw from the interview at any point and to choose to not answer questions that they did not feel comfortable with. Participants diagnosed with hazardous drinking had one didactic session where they were given information about the effects of heavy drinking on physical, psychological, social and occupational functioning.

\section{Results}

The sample comprised 315 participants. The response rate was $100 \%$, with all eligible participants completing the survey. The sample had a higher proportion of males (57.8\%) than females. The mean age of the sample was 41.1 years (s.d. = 11.3). Of the participants, $81.3 \%$ had completed secondary education or above and $73.1 \%$ of the participants were economically inactive.

The 1-year prevalence of drinking, hazardous drinking and alcohol dependence was $16.8 \%$ (95\% CI 12.9-21.4), 5.7\% (95\% CI 3.4-8.9) and 2.5\% (95\% CI 1.1-4.9) respectively. 


\begin{tabular}{|c|c|c|c|}
\hline Variable & $\begin{array}{l}\text { Abstainers } \\
(n=262)\end{array}$ & $\begin{array}{l}\text { Drinkers } \\
(n=53)\end{array}$ & $P$ \\
\hline $\begin{array}{l}\text { Gender, \% } \\
\text { Male } \\
\text { Female }\end{array}$ & $\begin{array}{l}74.7 \\
94.7\end{array}$ & $\begin{array}{c}25.3 \\
5.3\end{array}$ & $<0.001^{*}$ \\
\hline Mean age, years (s.d.) & $40.8(11.0)$ & $42.6(12.7)$ & 0.27 \\
\hline $\begin{array}{l}\text { Living arrangements, \% } \\
\text { Living with family } \\
\text { Living alone or in } \\
\text { supported housing }\end{array}$ & $\begin{array}{l}83.6 \\
75.0\end{array}$ & $\begin{array}{l}16.4 \\
25.0\end{array}$ & 0.37 \\
\hline $\begin{array}{l}\text { Marital status, } \% \\
\text { Married } \\
\text { Single or post-marital }\end{array}$ & $\begin{array}{l}87.4 \\
77.9\end{array}$ & $\begin{array}{l}12.6 \\
22.1\end{array}$ & $0.02^{*}$ \\
\hline $\begin{array}{l}\text { Education, \% } \\
\text { None } \\
\text { Completed primary } \\
\text { education } \\
\text { Completed secondary } \\
\text { education } \\
\text { Completed higher } \\
\text { secondary education } \\
\text { or above }\end{array}$ & $\begin{array}{l}95.8 \\
68.6 \\
84.8\end{array}$ & $\begin{array}{c}4.2 \\
31.4 \\
15.2 \\
17.7\end{array}$ & $0.04^{*}$ \\
\hline $\begin{array}{l}\text { Occupation, \% } \\
\text { Economically active } \\
\text { Economically inactive }\end{array}$ & $\begin{array}{l}72.6 \\
87.0\end{array}$ & $\begin{array}{l}27.4 \\
13.0 \\
\end{array}$ & $0.003^{*}$ \\
\hline $\begin{array}{l}\text { Recipient of disability } \\
\text { benefits, \% } \\
\text { No } \\
\text { Yes }\end{array}$ & $\begin{array}{l}84.1 \\
77.3\end{array}$ & $\begin{array}{l}15.9 \\
22.7\end{array}$ & 0.26 \\
\hline
\end{tabular}

${ }^{*}$ Value significant at $<0.05$.

The sociodemographic profiles of drinkers and abstainers are compared in Table 1. A significantly higher proportion of males, participants with at least primary education, economically active participants and single/post-marital participants were drinkers.

The most preferred drink was beer (36.2\%), followed by Indian-made foreign liquor (25.5\%). Of the current drinkers, $63.3 \%$ drank in bars and $14.3 \%$ drank at home; $63.3 \%$ had started drinking before the age of 25 years; and $11.3 \%$ reported morning drinking. Hazardous drinkers exclusively drank spirits (66.7\%) and country liquor (33.3\%), while casual drinkers were more likely to drink beer (53.1\%); $87.5 \%$ of hazardous drinkers drank in bars, but only $51.5 \%$ of casual drinkers drank in bars. Compared with casual drinkers (5.7\%), a higher proportion of hazardous drinkers $(22.2 \%)$ reported morning drinking.

Compared with abstainers, higher proportions of drinkers had a longer duration of schizophrenic illness, mental illness in first-degree relatives, more in-patient stays on a mental health ward, and longer mean in-patient stays. A higher proportion of abstainers, however, had more than 12 out-patient visits in the past year compared with drinkers. Drinkers were more likely to be on typical antipsychotics or depot antipsychotics than abstainers; but abstainers were on higher mean doses of antipsychotics in chlorpromazine equivalents compared with drinkers. None of these findings are statistically significant at $P<0.05$. The only statistically significant difference was that a higher proportion of drinkers were on combination psychotropics compared with abstainers.

A higher proportion of hazardous drinkers had an illness duration of more than 10 years compared with casual drinkers $(77.8 \%$ v. $60 \%, P=0.19)$. Hazardous drinkers were more likely than casual drinkers to have two or more admissions in the past year $(22.2 \%$ v. $2.9 \%, P=0.06)$ and a longer mean in-patient stay (24.1 days $v .7 .8$ days, $P=0.12$ ). Hazardous drinkers were more often prescribed a combination of psychotropics compared with casual drinkers $(27.8 \%$ v. 22.9\%, $P=0.69)$ and needed higher mean chlorpromazine equivalent doses $(305.9 \mathrm{mg} v .296 .5 \mathrm{mg}$, $P=0.89$ ). Hazardous drinkers had higher BPRS scores compared with casual drinkers (10.9 v. 7.2, $P=0.06)$. None of these differences were clinically significant.

The BPRS scores (individual items and total) of drinkers and abstainers are compared in Table 2. The mean total BPRS score was significantly lower in drinkers compared with abstainers. The mean scores on the following items of the scale were significantly lower in drinkers compared with abstainers: somatic concerns, unusual thought content, hallucinations, conceptual disorganisation, blunted affect, emotional withdrawal, motor retardation, tension and uncooperativeness.

\section{Discussion}

This cross-sectional exploratory study assessed the prevalence and correlates of alcohol drinking and its impact on clinical outcome in patients with schizophrenia. The 12-month prevalence rates of alcohol consumption, hazardous drinking and alcohol dependence were $16.8 \%$, $5.7 \%$ and $2.5 \%$ respectively. This is lower than the prevalence of hazardous drinking in a primary care setting in Goa $(8.2 \%)^{47}$ and in people with psychotic disorder from São Paulo, Brazil (7.3\%). ${ }^{14}$ Furthermore, the rates are much lower than the rates of alcohol use disorder in the USA $(33.7 \%)^{2}$ and the UK (32\%). ${ }^{9}$ This further emphasises that the cultural and regional differences in alcohol use patterns that are prevalent in the community extend to clinical samples of people with severe mental illness. Researchers have argued that the prevalence of substance misuse in severe mental illness is associated with the use and availability of that particular substance in the general population; ${ }^{9}$ the low prevalence of alcohol use disorder in our sample is probably a reflection of the low prevalence of alcohol use disorder in the general population in India (current alcohol use $6 \%,{ }^{48}$ alcohol dependence $0.7 \%{ }^{49}$ ).

In our study, males were more likely than females to use alcohol, a finding that has been demonstrated in the general population in $\mathrm{Goa}^{47}$ and in people with mental health problems globally. ${ }^{23,50}$ Being unmarried or postmarital was significantly associated with drinking alcohol in our study. This is consistent with similar findings in other community $^{51}$ and clinic $^{13}$ studies. This probably points to the critical role of family and social pressures in substance misuse behaviour. Ongoing family support is known to be associated with substantial reductions in adverse outcomes of substance use. ${ }^{52}$ Contrary to earlier reports from highincome countries, ${ }^{1,21,51}$ in our study people who were economically active and had received formal education 


\begin{tabular}{|llll|}
\hline Table 2 & \multicolumn{3}{c}{$\begin{array}{l}\text { Brief Psychiatric Rating Scale (BPRS) scores in } \\
\text { schizophrenia }\end{array}$} \\
\cline { 2 - 4 } BPRS item & Abstainers & Drinkers & $P$ \\
\hline Disorientation & $0.88(1.35)$ & $0.73(1.14)$ & 0.45 \\
\hline Somatic concerns & $1.14(1.32)$ & $0.71(1.13)$ & $0.03^{*}$ \\
\hline Anxiety & $1.76(1.18)$ & $1.43(1.16)$ & 0.06 \\
\hline Guilt & $0.12(0.54)$ & $0.03(0.27)$ & 0.25 \\
\hline Depression & $0.03(0.24)$ & $0(0)$ & 0.37 \\
\hline Grandiosity & $0.14(0.55)$ & $0.13(0.62)$ & 0.91 \\
\hline Suspiciousness & $0.41(0.9)$ & $0.35(0.87)$ & 0.69 \\
\hline Hostility & $0.01(0.12)$ & $0(0)$ & 0.36 \\
\hline $\begin{array}{l}\text { Unusual thought } \\
\text { content }\end{array}$ & $0.72(1.22)$ & $0.33(0.8)$ & $0.03^{*}$ \\
\hline Hallucinations & $0.91(1.27)$ & $0.49(1.03)$ & $0.02^{*}$ \\
\hline $\begin{array}{l}\text { Conceptual } \\
\text { disorganisation }\end{array}$ & $1.75(1.79)$ & $0.98(1.42)$ & $0.003^{*}$ \\
\hline Blunted affect & $1.67(1.94)$ & $0.96(1.6)$ & $0.01^{*}$ \\
\hline Emotional withdrawal & $0.83(1.1)$ & $0.52(0.91)$ & $0.05^{*}$ \\
\hline Motor retardation & $0.25(0.75)$ & $0.01(0.13)$ & $0.02^{*}$ \\
\hline Tension & $1.35(1.86)$ & $0.6(1.3)$ & $0.005^{*}$ \\
\hline Uncooperativeness & $1.36(1.13)$ & $0.98(1.1)$ & $0.03^{*}$ \\
\hline Excitement & $0.25(0.8)$ & $0.24(0.7)$ & 0.9 \\
\hline $\begin{array}{l}\text { Mannerisms/ } \\
\text { posturing }\end{array}$ & $0(0)$ & $0(0)$ & \\
\hline Total & $13.64(10.28)$ & $8.45(6.92)$ & $<0.001^{*}$ \\
\hline
\end{tabular}

*Value significant at $<0.05$

were more likely to be drinkers compared with those who were economically inactive and illiterate. A similar association between employment and drinking has been shown in men attending private primary care clinics in Goa, ${ }^{47}$ where men who consumed any alcohol were more likely than abstainers to be employed. In another in-patient-based course and outcome study of substance misuse comorbidity in schizophrenia from India, it was reported that people misusing substances were more likely to be employed compared with those not using any substance. ${ }^{53}$ A possible explanation for this could be that in the absence of social security and pension schemes for chronically ill people in India, unlike in many high-income countries, only people with financial resources may be able to procure alcohol in India.

We did not find any significant association between drinking and clinical outcomes in schizophrenia, such as duration of illness, medication dosage or mental health service use. This may possibly be because the drinkers in our study were using alcohol at a less abusive level than the drinkers reported in other studies, especially from the USA. Some of our findings are supported by an Australian study that, despite having a high prevalence of substance misuse, could not demonstrate that substance misuse adversely affects the course of schizophrenia in terms of hospital admissions, suicide attempts or doses of antipsychotic drugs. ${ }^{13}$ Nevertheless, there is published evidence that heavy alcohol use is associated with adverse outcomes. In a study of community-dwelling people with chronic mental illness in Massachusetts, USA, ${ }^{21}$ people who misused substances were less able to manage their lives in the community compared with those who were not misusing any substance in terms of maintaining regular meals, adequate finances, stable housing and regular activities. They also showed greater hostility, suicidality and speech disorganisation, had poorer medication adherence and had increased rehospitalisation. A major finding in our study is that drinkers had significantly lower mean BPRS scores compared with non-drinkers. They had significantly low scores on all items that are considered negative symptoms of schizophrenia, namely blunted affect emotional withdrawal and motor retardation. There were also significantly low scores on the tension, uncooperativeness, somatic concerns, conceptual disorganisation and hallucination BPRS items. This may be at odds with earlier reports, ${ }^{16,17}$ but some studies have shown low BPRS scores in people with dual diagnosis compared with people with a single diagnosis. ${ }^{54}$ There is evidence for different patient profiles in dual diagnosis. Some patients have higher symptom levels and poor social skills, but other patients have lower symptom levels, especially negative symptoms, and better social skills compared with people with schizophrenia who do not misuse substances. ${ }^{55-57}$ Predominance of negative symptoms in people with schizophrenia who do not misuse substances has been reported from studies in India ${ }^{53}$ and other LAMI settings. ${ }^{14}$ There are also supporters of the self-medication theory, which suggests that by misusing psychoactive substances, people with schizophrenia relieve their negative symptoms. ${ }^{58}$

From our study, the profile of a person with schizophrenia who drinks alcohol is a single or post-marital male who is economically active, has received formal education, has a lower symptom burden, especially of negative symptoms, and has adverse illness outcomes compared with patients who abstain from drinking. In our opinion, the lower symptom scores on the BPRS and the absence of adverse outcomes in drinkers is not an outcome of drinking behaviour. Cultural context in the use of alcohol may have a role to play. In high-income countries, deinstitutionalisation is considered to have put patients at risk of misusing substances. ${ }^{9}$ In the Indian setting, patients are more often under supervision of their families. Although alcohol is freely available, especially in Goa, drinking is not as ubiquitous in India as in high-income countries. Only patients with fewer deficit symptoms and with financial resources would be able to procure alcohol for consumption. It has been suggested that patients with more severe negative symptoms and premorbid functioning characterised by social isolation may lack the exposure to illicit substances or the social skills necessary to obtain them regularly to develop a drug use disorder. ${ }^{59}$ We can effectively conclude, therefore, that drinking alcohol is a result of better clinical outcomes and consequent better social functioning rather than the other way round.

Although people with schizophrenia who drank alcohol fared better symptomatically than abstainers, the subanalysis of drinkers showed a trend for worse outcomes with rising levels of drinking. Hazardous drinkers in our study had a longer illness duration, had more and 
longer in-patient admissions, needed more and higher doses of medication, and had higher BPRS scores. The drinking profile also worsens in hazardous drinkers, with hazardous drinkers exclusively drinking spirits and country liquor with a high alcohol content. Hazardous drinking is also more likely to occur in bars, and there are higher reports of morning drinking. These findings are in keeping with earlier studies on hazardous drinking. ${ }^{41}$

The main limitations of our study relate to the crosssectional design, which does not allow us to determine the direction of causality of the detected associations. Furthermore, our sample is relatively small, in keeping with the exploratory nature of our study. Finally, the lack of a validated vernacular version of an instrument such as the Structured Clinical Interview for DSM Disorders means that we had to rely on clinical diagnosis to identify people with schizophrenia. Our findings do show certain trends that are different from those seen in studies conducted in highincome countries. This strengthens the case for conducting a more comprehensive study, with a larger sample size, exploring the long-term course and outcomes of people with schizophrenia and comorbid alcohol use in India and other LAMI countries. As our sample was derived from a tertiary care mental health service, there is a potential for selection bias leading to overestimation of prevalence rates, as is common in specialist clinic-based studies. Since Goa is a small state, with the tertiary care hospital being easily accessible to the whole population, however, it is possible that our findings will be a true reflection of alcohol use in a community sample of people with psychotic disorders. The reliability of responses given in interviews to sensitive questions about one's alcohol use is uncertain. The data in our study were built on standardised assessment instruments such as the AUDIT and BPRS, which have established reliability allowing direct comparisons with other studies. Finally, because of the stigma attached to mental health problems, there is the possibility of underreporting of use of mental health services by the participants. There could also have been underreporting of alcohol consumption, especially since the data collectors were also involved in the clinical care of some of the participants. Alternative methods for independent verification of self-reports of such sensitive behaviours would not have been cost-effective, feasible or ethical, however. The alternative of using a self-administered questionnaire would have come with the attendant disadvantage of poor response rates.

\section{About the authors}

Anil Rane is a consultant psychiatrist at the Institute of Psychiatry and Human Behaviour, Goa, India. Abhijit Nadkarni is a Wellcome Trust research fellow at the London School of Hygiene and Tropical Medicine, UK. Jaiprada Kanekar and Wenona Fernandes are resident doctors and Hirabai A. Borker and Yvonne Pereira are consultant psychiatrists at the Institute of Psychiatry and Human Behaviour, Goa, India.

\section{References}

1 Mueser KT, Yarnold PR, Levinson DF, Singh H, Bellack AS, Kee K, et al. Prevalence of substance abuse in schizophrenia: demographic and clinical correlates. Schizophr Bull 1990; 16: 31-56.
2 Regier DA, Farmer ME, Rae DS, Locke BZ, Keith SJ, Judd LL, et al. Comorbidity of mental disorders with alcohol and other drug abuses. J Am Med Assoc 1990; 264: 2511-8.

3 Westermeyer J. Schizophrenia and substance abuse. In Review of Psychiatry, Vol. 11) (eds Tasman A, Riba MR): 379-401. American Psychiatric Press, 1992.

4 Drake RE, Osher FC, Noordsy DL, Hurlbut SC, Teague GB, Beaudett MS Diagnosis of alcohol use disorders in schizophrenia, Schizophr Bull 1990; 16: $57-67$.

5 El-Guebaly N, Hodgkins, DC. Schizophrenia and substance abuse: prevalence issues. Can J Psychiatry 1992; 37: 704-10.

6 Selzer JA, Lieberman JA. Schizophrenia and substance abuse. Psychiatr Clin North Am 1993; 16: 401-12.

7 Abou-Saleh MT, Janca A. The epidemiology of substance misuse and comorbid psychiatric disorders. Acta Neuropsychiatr 2004; 16: 3-8.

8 Schifano F. European dimensions of dual diagnosis. In Dual Diagnosis: Substance Misuse and Psychiatric Disorders (ed. GH Rassool): 58-65. Blackwell Science, 2002.

9 Menezes PR, Johnson S, Thornicroft G, Marshall J, Prosser D, Bebbington $\mathrm{P}$, et al. Drug and alcohol problems among individuals with severe mental illnesses in south London. Br J Psychiatry 1996; 168: 612-9.

10 Cantwell R, Brewin J, Glazebrook C, Dalkin T, Fox R, Medley I, et al. Prevalence of substance misuse in first-episode psychosis. $\mathrm{Br}$ Psychiatry 1999; 174: 150-3.

11 Graham HL, Maslin J, Copello A, Birchwood M, Mueser K, McGovern D, et al. Drug and alcohol problems amongst individuals with severe mental health problems in an inner city area of the UK. Soc Psychiatry Psychiatr Epidemiol 2001; 36: 448-55.

12 Duke PJ, Pantelis C, Barnes TR. South Westminster schizophrenia survey. Alcohol use and its relationship to symptoms, tardive dyskinesia and illness onset. Br J Psychiatry 1994; 164: 630-6.

13 Fowler IL, Can VJ, Carter NT, Lewin TJ. Patterns of current and lifetime substance use in schizophrenia. Schizophr Bull 1998; 24: 443-55.

14 Menezes PR, Ratto LR. Prevalence of substance misuse among individuals with severe mental illness in São Paulo. Soc Psychiatry Psychiatr Epidemiol 2004; 39: 212-7

15 Verma SK, Subramaniam M, Chong S, Kua EH. Substance abuse in schizophrenia: a Singapore perspective. Soc Psychiatry Psychiatr Epidemiol 2002; 37: 326-8.

16 Swofford CD, Scheller-Gilkey G, Miller AH, Woolwine B, Mance R. Double jeopardy: schizophrenia and substance use. Am J Drug Alcohol Abuse 2000; 26: 343-53.

17 Inderbitzin LB, Scheller-Gilkey G, Lewine RJ. A double-blind dosage reduction trial of fluphenazine decanoate in chronic, unstable schizophrenic patients. Am J Psychiatry 1994; 151: 1753-9.

18 Bowers MB, Mazure CM, Nelson CJ, Jatlow PI. Psychotogenic drug use and neuroleptic response. Schizophr Bull 1990; 16: 81-5.

19 Swofford CD, Kasckow JW, Scheller-Gilkey G, Inderbitzin LB. Substance use: a powerful predictor of relapse in schizophrenia. Schizophr Res 1996; 20: 145-51.

20 Haywood TW, Kravitz HM, Grossman LS, Cavanaugh Jr JL, Davis JM Lewis DA. Predicting the revolving door phenomenon among patients with schizophrenic, schizoaffective, and affective disorders. Am J Psychiatry 1995; 152: 856-61.

21 Drake RE, Wallach MA. Substance abuse among the chronic mentally ill. Hosp Community Psychiatry 1989; 40: 1041-6.

22 Drake RE, Osher FC, Wallach MA. Alcohol use and abuse in schizophrenia. J Nerv Ment Dis 1989; 177: 408-13.

23 Margolese HC, Negrete JC, Tempier R, Gill K. A 12-month prospective follow-up study of patients with schizophrenia-spectrum disorders and substance abuse: changes in psychiatric symptoms and substance use. Schizophr Res 2006; 83: 65-75.

24 Cournos F, Empfield,M, Horwath E, McKinnon K, Meyer I, Schrage H et al. HIV prevalence among patients admitted to two psychiatric hospitals. Am J Psychiatry 1991; 148: 1225-9. 
25 Rosenberg SD, Goodman LA, Osher FC, Swartz MS, Essock SM, Butterfield $\mathrm{MI}$, et al. Prevalence of HIV, hepatitis B and hepatitis $\mathrm{C}$ in people with severe mental illness. Am J Public Health 2001; 91: 31-7.

26 Bartels SJ, Drake RE, McHugo G. Alcohol abuse, depression, and suicidal behavior in schizophrenia. Am J Psychiatry 1992; 149: 394-5.

27 Swartz MS, Swanson JW, Hiday V, Borum R, Wagner HR, Burns BJ, et al. Violence and severe mental illness: the effects of substance abuse and non-adherence to medication. Am J Psychiatry 1998; 15: 226-31.

28 Goodman LA, Salyers MP, Mueser KT, Rosenberg SD, Swartz M, Essock SM, et al. Recent victimization in women and men with severe mental illness: prevalence and correlates. J Trauma Stress 2001; 14: 615-32.

29 Abram K, Teplin L. Co-occurring disorders among mentally ill jail detainees: implications for public policy. Am J Psychologist 1991; 46: $1036-44$.

30 Caton C, Shrout P, Eagle P, Opler LA, Felix A, Dominguez B. Risk factors for homelessness among schizophrenic men: a case-control study. Am J Public Health 1994; 84: 265-70.

31 Dixon L, McNary S, Lehman A. Substance abuse and family relationships of persons with severe mental illness. Am J Psychiatry 1995; 152: 456-8.

32 Brunette MF, Mueser KT, Xie H, Drake RE. Relationships between symptoms of schizophrenia and substance abuse. J Nerv Ment Dis 1997; 185: $13-20$.

33 Alterman Al, Ayre FR, Williford WO. Diagnostic validation of conjoint schizophrenia and alcoholism. J Clin Psychiatry 1984; 5: 300-3.

34 Cuffel BJ, Heithhoff KA, Lawson W. Correlates of patterns of substance abuse among patients with schizophrenia. Hosp Community Psychiatry 1993; 44: 247-51.

35 Serper MR, Alpert M, Richardson NA, Dickson S, Allen MH, Werner A. Clinical effects of recent cocaine use on patients with acute schizophrenia. Am J Psychiatry 1995; 152: 1464-9.

36 Rosenthal RN, Hellerstein KJ, Miner CR. Positive and negative syndrome typology in schizophrenic patients with psychoactive substance use disorders. Compr Psychiatry 1994; 35: 91-8.

37 Sevy S, Kay SR, Opler LA, van Praag HM. Significance of cocaine history in schizophrenia. J Nerv Ment Dis 1990; 178: 642-8.

38 Xafenias A, Diakogiannis I, lacovides A, Fokas K, Kaprinis G. Factors affecting hospital length of stay: is substance use disorder one of them? A study in a Greek public psychiatric hospital. Am J Addict 2008; 17 447-51.

39 Saunders JB, Aasland OG, Babor TF, Fuente JR, Grant M. Development of the Alcohol Use Disorders Identification Test (AUDIT): WHO collaborative project on early detection of persons with harmful alcohol consumption - II. Addiction 1993; 88: 791-804.

40 Babu RS, Sengupta SN. A study of problem drinkers in a general hospital. Indian J Psychiatry 1997; 39: 13-7.

41 Gaunekar G, Patel V, Rane A. The impact and patterns of hazardous drinking amongst male industrial workers in Goa, India. Soc Psychiatry Psychiatr Epidemiol 2005; 40: 267-75.

42 Gaunekar G, Patel V, Jacob KS, Vankar G, Mehan D, Rane A, et al Drinking patterns of hazardous drinkers: a multicenter study in India. In Moonshine Markets: Issues in Unrecorded Alcohol Beverage Production and
Consumption (eds A Howarth, R Simpson): 122-41. Brunner-Routledge, 2004

43 Silva MC, Gaunekar G, Patel V, Kukalekar DS, Fernandes J. The prevalence and correlates of hazardous drinking in industrial workers: a study from Goa, India. Alcohol Alcohol 2003; 38: 79-83.

44 World Health Organization. ICD-10 Classification of Mental and Behavioural Disorders, Diagnostic Criteria for Research. WHO, 1993.

45 Overall JE, Gorham DR. The brief psychiatric rating scale. Psychol Rep 1962; 10: 799-812.

46 Nagaraj AK, Pai NB, Rao S. A comparative study of sexual dysfunction involving risperidone, quetiapine and olanzapine. Indian J Psychiatry 2009; 51: 265-71.

47 D'Costa G, Nazareth I, Naik D, Vaidya R, Levy G, Patel V, et al. Harmful alcohol use in Goa, India, and its associations with violence: a study in primary care. Alcohol Alcohol 2007; 42: 131-7.

48 Ray R, Mondal AB, Gupta K, Chatterjee A, Bajaj P. The Extent, Pattern and Trends of Drug Abuse in India: National Survey. United Nations Office on Drugs and Crimes and Ministry of Social Justice and Empowerment, Government of India, 2004.

49 Reddy MV, Chandrashekar CR. Prevalence of mental and behaviora disorders in India: a meta-analysis. Indian J Psychiatry 1998; 40: 149-57.

50 Mueser KT, Yarnold PR, Rosenberg ST, Swett Jr C, Miles KM, Hill D. Substance use disorder in hospitalised severely mentally ill psychiatric patients: prevalence, correlates and subgroups. Schizophr Bull 2000; 26: 179-92.

51 Hall W, Teesson M, Lynskey M, Degenhardt L. The 12-month prevalence of substance use and ICD-10 substance use disorders in Australian adults: findings from National Survey of Mental Health and Well Being. Addiction 1999; 94: 1541-50.

52 Fischer EP, McSweeney JC, Pyne JM, Williams DK, Naylor AJ, Blow FC et al. Influence of family involvement and substance use on sustained utilisation of services for schizophrenia. Psychiatr Serv 2008; 59: 902-8.

53 Aich TK, Sinha VK, Khess C, Singh S. Substance abuse co-morbidity in schizophrenia: an in-patient study of course and outcome. Indian $J$ Psychiatry 2005; 47: 33-8.

54 Blow FC, Barry KL, Bootsmiller BJ, Copeland LA, McCormick R, Visnic S. Longitudinal assessment of inpatient use and functioning of seriously mentally ill veterans with and without co-occurring substance use disorders. J Psychiatr Res 2008; 32: 311-9.

55 Arndt S, Tyrrell G, Flaum M, Andreasen NC Comorbidity of substance abuse and schizophrenia: the role of pre-morbid adjustment. Psychol Med 1992; 22: 379-88.

56 Dixon L, Haas G, Weiden PJ, Sweeney J, Frances AJ. Drug abuse in schizophrenic patients: clinical correlates and reasons for use. Am Psychiatry 1994; 148: 224-30.

57 Salyers MP, Mueser KT. Social functioning, psychopathology, and medication side effects in relation to substance use and abuse in schizophrenia. Schizophr Res 2001; 48: 109-23.

58 Potvin S, Sepehry A, Stip E. A meta-analysis of negative symptoms in dual diagnosis schizophrenia. Psychol Med 2006; 36: 431-40.

59 Cohen M, Klein DF. Drug abuse in a young psychiatric population. Am J Orthopsychiatry 1970; 40: 448-55. 